\title{
The licensing condition on clausal ellipsis
}

\author{
Enrico Boone \\ Leiden University
}

This paper is concerned with the correct characterization of the licensing condition on clausal ellipsis and how it relates to the distribution of ellipsis. I argue, essentially following López (2000), that ellipsis is licensed when the ellipsis clause bears a relation to an antecedent in the discourse component. A relation between two discourse units can be established in two ways: (1) Either there holds a direct relation between the two discourse units or (2) there holds an anaphoric relation mediated by a discourse anaphor. In this paper, I show how this two-way distinction in setting up discourse relations accounts for the two-way split we find in the distribution of ellipsis.

Keywords: Gapping, Fragments, Sluicing, licensing condition on ellipsis, discourse component

\section{Introduction}

There is a growing body of literature arguing that clausal ellipsis involves a fullfledged syntactic structure from which the elements that survive ellipsis, the so-called 'remnants', have been extracted (e.g. Merchant 2001). Under such an approach to ellipsis, Gapping (i.e. deletion in a coordination), Fragments (i.e. deletion in a stand-alone utterance) and Sluicing (i.e. deletion in an interrogative sentence) are virtually identical when it comes to their syntax, as shown in (1).

(1) a. Max ate the apple and $\left[_{\mathrm{DP}} \text { Sally }\right]_{i}\left[_{\mathrm{DP}} \text { the hamburger }\right]_{j}\left[t_{i}-\right.$ ate $\left.t_{j}\right]$. Gapping b. A: Who did you see?

B: $\left[{ }_{\text {DP }} \text { Sally }\right]_{i}\left[\text { I t }_{i}\right]_{3}$

Fragments

c. Anne saw someone, but I don't know $\left[_{\mathrm{DP}} \text { who }\right]_{i}\left[\right.$ Anne $\left.t_{i}\right]$. Sluicing

The fact that the ellipsis types in (1) are syntactically similar begs the question whether they should be formally distinguished. One reason to suspect that they should be is that these ellipsis types have a different distribution. Gapping occurs 
in the second conjunct of a coordination, Fragments in a stand-alone utterance, and Sluicing in an interrogative sentence. Whether or not these distinctions follow from a grammatical difference arguably depends on how these ellipsis types are licensed; after all, the distribution of ellipsis is generally taken to be governed by the licensing condition on ellipsis. In this paper, I argue that ellipsis licensing takes place in the discourse component and not in the syntax. Specifically, I argue that ellipsis is licensed when the ellipsis clause can be linked to an antecedent in the discourse. I show that this single licensing condition naturally explains the twoway split found in the distribution of different clausal ellipsis types.

\section{The distribution of Gapping, Fragments and Sluicing}

It is a well-known property of Gapping that the ellipsis site cannot be subordinated with respect to its antecedent (Jackendoff 1971). (2), for example, illustrates that Gapping cannot occur in an embedded clause. Here, Gapping is embedded under the matrix clause headed by know, while the antecedent is not.

(2) ${ }^{\star}$ Harry has invited Sue and I know (that) Bill Mary.

A fact that has received little attention in the literature is that this restriction also holds for Fragments (Hankamer 1979). ${ }^{1}$ This is illustrated in (3).

(3) A: Who has John invited?

B: ${ }^{\star}$ k know Mary

Interestingly, this restriction on embedding is particular to Gapping and Fragments. Sluicing is not constrained this way, as can be seen in (1c), repeated here as (4).

(4) Anne saw someone, but I don't know who Anne saw.

Johnson (2009) shows that the antecedent of Gapping cannot be embedded with respect to the ellipsis clause either. (5) shows that the clause embedded under she's said cannot be the antecedent for the instance of Gapping in the second conjunct. (6) illustrates that Fragments pattern with Gapping in this respect. Only B's response is an acceptable answer to A's question, the response in $\mathrm{B}^{\prime}$ is not.

(5) * [She’s said [Peter has eaten his peas]] and [Sally has eaten her green beans], so now we can have dessert.

(6) A: What did she say Peter has eaten?

B: Peas she said Peter has eaten.

$\mathrm{B}^{\prime}$ : ${ }^{*}$ Peas Peter has eaten (but I don't know if that is what she said). 
Once again, Sluicing patterns differently. The restriction on having an embedded antecedent does not hold for Sluicing, as shown in (7).

(7) John knows he should eat something, but he just can't decide what.

One might suspect at this point that Gapping and Fragments, as opposed to Sluicing, are main clause phenomena that do not occur in embedded contexts. The example of Gapping in (8) shows that this is not the case. Gapping can be embedded, but only if the antecedent is embedded too.

(8) I know that [[Harry has invited Sue] and [Bill Mary]].

The restriction on subordinating Gapping also subsumes cases in which the ellipsis clause occurs in an adverbial clause, as in (9).

(9) ${ }^{\star}$ Max ate the apple, because Sally the hamburger.

It is not possible to test whether Fragments occur in syntactic subordinations, because in Fragments the elliptical clause is not syntactically connected to another clause. Sluicing, however, yet again patterns differently from Gapping.

(10) Harry has invited someone, although I don't know who Harry has invited.

The facts presented in this section give rise to two questions. First, what underlies the no subordination restriction on Gapping and Fragments? Second, why does Sluicing pattern differently from Gapping and Fragments? The distribution of ellipsis is generally believed to be governed by the licensing condition. If so, a theory of the licensing condition on ellipsis should address these two questions.

\section{Theories on licensing ellipsis}

In this section, I concentrate on how Sluicing is licensed. I first consider the syntactic licensing accounts proposed by Lobeck (1995) and Merchant (2001), which hold that ellipsis is licensed by a functional head in the syntax (the licensor). I then turn to discuss the discourse accounts of licensing by López (2000) and AnderBois (2011).

\subsection{Licensing ellipsis in the syntax}

The licensing condition on ellipsis is postulated to capture the fact that not every context allows for (every type of) ellipsis. Sluicing is possible after an interrogative wh-phrase, as in (11), but not after a relative pronoun (cf. van Riemsdijk 1978; Lobeck 1995), as illustrated in (12). 
(11) a. Somebody just left - guess who teft.

b. Anne invited someone, but I don't know who Anne invited.

(12) * Someone has done the dishes, but I don't know the person who.

(Kim 1997: 157)

Syntactic licensing theories hypothesize that licensing is a formal syntactic requirement that must be met for ellipsis to take place successfully. Lobeck (1995) proposes that ellipsis is licensed by a proper head-governor specified for strong agreement (i.e. productive agreement that is spelled out on either Probe or Goal), parallel to how pro in null subject languages is licensed by the agreement on the verb. For Sluicing, Lobeck argues that a $[+\mathrm{wH}]$ feature on $\mathrm{C}$ gives rise to strong agreement and therefore licenses ellipsis. To rule out Sluicing in relative clauses (cf. (12)), Lobeck follows Rizzi (1990) in assuming that in those cases $C$ is equipped with a $[-\mathrm{wH}]$-feature, which does not give rise to strong agreement and therefore does not license ellipsis.

Merchant (2001), on the other hand, argues that ellipsis is licensed by an E-feature, which has a syntactic requirement (13a) and a semantic requirement (13b). When both are met, ellipsis takes place in the phonological component (13c).

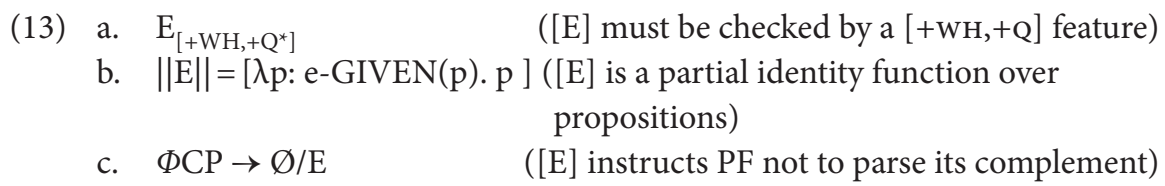

Relevant for our discussion on the licensing condition is the syntactic requirement in (13a). It is this requirement that sets apart (11) from (12). Under Merchant's account, ellipsis is only licensed when $[\mathrm{E}]$ is checked by a $[+\mathrm{WH},+\mathrm{Q}]$ feature. In (12), ellipsis is not licensed because the $w h$-phrase is [+WH]. In lack of a specification for $\mathrm{Q}$, the $[+\mathrm{WH}]$ feature of the relative pronoun fails to satisfy [E]'s checking requirement. Consequently, ellipsis is not licensed.

What is problematic in both Lobeck's and Merchant's account is that the accounts lack explanatory force. In general, the distribution of ellipsis is accounted for by postulating that the licensor must partake in a particular Agree relation. Why do some Agree relations license ellipsis while others do not? This brings us to another problem for syntactic licensing theories, namely the distribution of Gapping and Fragments. As we saw in Section 2, Gapping and Fragments are subject to a no subordination restriction. Without any amendments, the syntactic licensing theory cannot account for this restriction. The reason is that the licensing condition on ellipsis is satisfied within the ellipsis clause (namely when a particular Agree relation is established). This means that ellipsis is licensed at a point 
when there is no relation yet between the ellipsis clause and its antecedent. The no subordination restriction on Gapping and Fragments signals that ellipsis site and antecedent must be in a particular relation for ellipsis to be licensed. Moreover, there does not seem to be a licensing element involved in Gapping and Fragments. Hence, there is no evidence that any Agree relation takes place that licenses ellipsis in these constructions.

\subsection{Licensing ellipsis in the discourse component}

In response to the problems evoked by a syntactic theory of ellipsis licensing, López (2000) developed an account in which ellipsis is licensed in the discourse component. Specifically, López argues that ellipsis licensors establish a discourse relation with the antecedent. I refer to this property as DIscourse-linking. The core idea of López's account is that ellipsis sites are unable to retrieve an antecedent in and of themselves. Therefore, the ellipsis site must be linked to an antecedent in the discourse. In Sluicing, DISCOURSE-linking is mediated by the licensor, namely the $w h$-phrase. ${ }^{2}$ Support for this idea comes from the fact that aggressively non D-linked wh-phrases do not license Sluicing, as shown in (13).

(13) ${ }^{\star}$ I know Pat wants to buy something, but I don't know what the hell.

(López 2000: 185)

AnderBois (2011) provides further support for the idea that the wh-phrase in Sluicing establishes a discourse link with an antecedent. He observes that Sluicing is impossible when the antecedent of the sluice is contained in an appositive.

(14) a. * Joe, who once killed a man in cold blood, doesn't even remember who.

b. ${ }^{\star}$ Amy, who coined a new word last night, forgot what.

To account for these data, AnderBois adopts the idea from Kratzer \& Shimoyama (2002) that one of the properties of indefinites is that they evoke a set of alternatives. This set of alternatives is said to introduce an issue into the discourse as to which alternative holds. According to AnderBois, a sluice anaphorically retrieves this issue. In that case, there is an anaphoric discourse relation between the interrogative $w h$-phrase and the indefinite correlate. Based on these facts, we can formulate the licensing condition on clausal ellipsis as in (15).

(15) Licensing condition on clausal ellipsis

Ellipsis is licensed when the ellipsis clause is DISCOURSE-linked to an antecedent.

Given (15), the ungrammaticality of the Sluicing example in (12) follows from the fact that the $w h$-phrase is not an interrogative wh-phrase. Under AnderBois' 
hypothesis that only interrogative wh-phrases are anaphors to issues, the noninterrogative wh-phrase in (12) does not license Sluicing, since Sluicing is only licensed when it is DIscourse-linked to an antecedent. The wh-phrase in (13), being aggressively non D-linked, likewise does not have the property of DISCOURSElinking. In general, ellipsis in (12) and (13) is not licensed because ellipsis cannot be resolved. In order for ellipsis to be resolved, the ellipsis clause must be DISCOURSE-linked to an antecedent.

\section{Licensing Gapping and Fragments}

In this section, I propose, in accordance to (15), that Gapping and Fragments are licensed in a particular discourse configuration. To this end, I will first introduce my assumptions about the discourse component.

\subsection{Discourse representations}

I adopt the idea that discourse representations consist of tree structures. Discourse relations within this representation can be established in two ways; either there is a direct relation between two discourse units (e.g. through use of a connective) or there is an anaphoric relation between two discourse units (e.g. through use of adverbials such as then and instead, see Webber, Joshi, Stone \& Knott 2003).

In the discourse literature, a distinction is generally made between coordination and subordination (see e.g. Asher \& Vieu 2005). To avoid confusion in terminology, I reserve the terms 'coordination' and 'subordination' to describe syntactic structures and use the terms 'hierarchical' (semantically asymmetrical) and 'nonhierarchical' (i.e. semantically symmetrical) to describe discourse relations (following Blühdorn 2008). Culicover \& Jackendoff (1997) argue that whether or not a relation is hierarchical or non-hierarchical cannot be read off from the syntax (cf. Blühdorn 2008). This means that the distinction between hierarchical or nonhierarchical interpretation must be the outcome of an interpretative procedure. As Culicover \& Jackendoff (1997) point out, the postulation of this mapping procedure means that there cannot be a one-to-one mapping between coordination and subordination on the one hand, and hierarchical versus non-hierarchical interpretation on the other. I propose that the postulation of this mapping procedure is not just needed to account for the fact that there is no one-to-one mapping between syntax and interpretation, but that it is independently needed to determine the interpretation of discourse relations. To see this, consider a case in which two clauses S1 and S2 are not connected syntactically, as in the following examples. 
(16) a. [ ${ }_{S 1}$ John lives in Italy] [ $\mathrm{S}_{\mathrm{S} 2}$ Mary lives in Spain]

b. [ ${ }_{S 1}$ John got upset] [ ${ }_{S 2}$ The chocolate cookies were sold out]

In (16a), S1 and S2 have equal status. In other words, the relation between S1 and S2 is symmetrical: Neither S1 nor S2 selects or modifies the other. In (16b), on the other hand, the most salient reading is that S2 specifies the reason for S1 (John got upset, because the chocolate cookies were sold out). According to Blühdorn (2008), there are three types of hierarchical interpretations, namely cause-effect (e.g. S1 because S2), conditional (e.g. if S1 then S2) and situating (e.g. S1 before S2). Since there are no overt indicators in (16) that specify whether there is a hierarchical or non-hierarchical relation between S1 and S2, there must be an interpretative mapping procedure that underlies this distinction. This mapping procedure is responsible for (16a) mapping onto a discourse representation in which S1 and S2 are non-hierarchically related and (16b) mapping onto a discourse representation in which there is a hierarchical relation between S1 and S2. For expository purposes, I adopt Asher's (1993) notation in which a non-hierarchical relation is marked as ' $\rightarrow$ ' and a hierarchical relation is marked as ' $\downarrow$ '.

(17) a. Non-hierarchical relation

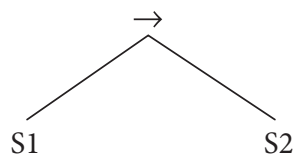

b. Hierarchical relation

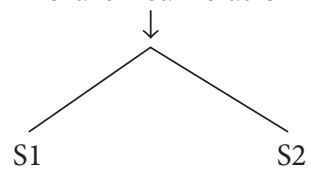

I propose that the mapping procedure that maps (16a) to (17a) and (16b) to (17b) to be the same mapping procedure that determines whether the cases in (18) involve hierarchical or non-hierarchical relations.

(18) a. [ ${ }_{\mathrm{S} 1}$ John lives in Italy] and [ ${ }_{\mathrm{S} 2}$ Mary lives in Spain]

b. $\quad\left[{ }_{S 1}\right.$ John got upset] because $\left[_{\mathrm{S} 2}\right.$ the chocolate cookies were sold out]

This view is in accordance with the hypothesis that whether or not a relation is hierarchical or not cannot be read off from the syntax. A consequence of this view is that (18a) and (18b) are fully equivalent to the cases in (16a) and (16b), respectively, when it comes to discourse representation. With this background, I now return to Gapping and Fragments.

\subsection{The licensing condition on Gapping and Fragments}

In light of the distribution of Gapping and Fragments discussed in Section 2, I propose the discourse licensing condition on Gapping and Fragments in (19). The licensing configuration is schematically represented in (20). 
(19) Licensing condition on Gapping and Fragments

Gapping and Fragments are licensed when ellipsis and antecedent are in a non-hierarchical relation in the discourse.

(20) Discourse configuration that licenses ellipsis

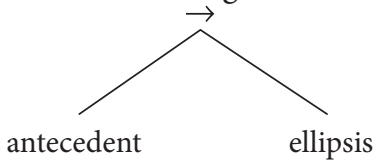

I now show how (19) captures the facts discussed in Section 2. I start by showing how a simple case of Gapping is licensed by (19).

(21) Max ate the apple and $\left[_{D P} \text { Sally }\right]_{i}\left[_{D P} \text { the hamburger }\right]_{j}\left[t_{t}\right.$-ate $\left.t_{j}\right]$

Gapping is licensed here because S1 and S2 have equal status in (21). That is, no hierarchical relation holds between S1 and S2. Therefore, the example in (21) is mapped onto the discourse representation in (20), in which ellipsis is correctly predicted to be licensed by (19). This account predicts that Gapping is not possible in coordinations where the interpretation is hierarchical. This prediction is borne out, as shown by the examples in (22). Gapping in (22a) is out under a conditional reading and in (22b) under a cause-effect reading. ${ }^{3}$

(22) a. ${ }^{\star}$ Big Louie steals one more car radio and Little Louie steals the hubcaps. conditional interpretation

(Culicover \& Jackendoff 1997)

b. * Sue became upset and Dan became downright angry. cause-effect interpretation

(Levin \& Princeo 1986)

Ellipsis in Fragments is also correctly predicted to be licensed by (19). A typical instance of question-answer Fragments is given in (23). In absence of a hierarchical interpretation, the relation between S1 and S2 is non-hierarchical. (23) thus has a discourse representation like the one in (20) and ellipsis is therefore correctly predicted to be licensed by (19).

(23) A: [ ${ }_{S 1}$ Who did you see?]

B: $\left[{ }_{S 2}\right.$ Bill $]$

In Section 2, we saw that Gapping and Fragments are restricted in that the ellipsis clause may not be subordinated with respect to its antecedent. The licensing condition in (19) captures this. Consider again the following examples which illustrate the no embedding restriction.

$(24){ }^{*}\left[_{S 1}\right.$ Harry has invited Sue $]$ and $\left[{ }_{S 2}\right.$ I know $\left[{ }_{S 3}\right.$ (that) Bill Mary. $\left.]\right]$

(25) a. [S Who has John invited?]

b. ${ }^{*}\left[{ }_{\mathrm{S} 2}\right.$ I know $\left[{ }_{\mathrm{S} 3}\right.$ Mary $\left.]\right]$ 
The discourse representation for both (24) and (25) is given in (26). Ellipsis is ruled out in (24) and (25) because the configuration in (26) is not one in which ellipsis is licensed. For ellipsis to be licensed, the ellipsis clause needs to be in a non-hierarchical relation with the antecedent (as in (20)), which is not the case here. In (26), S3 is in a relation with S2, but not with S1.

(26) Discourse tree of (24) and (25)

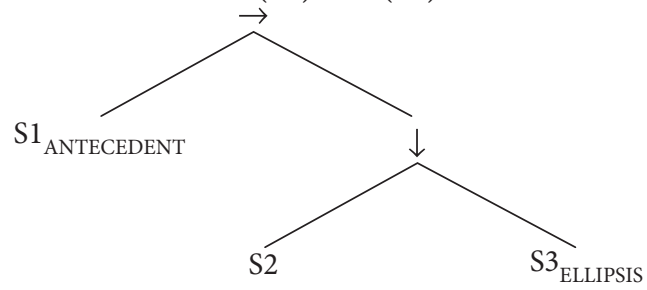

Recall that symmetrical embedding of ellipsis clause and antecedent, as in (27), is grammatical.

(27) $\left[{ }_{S 1}\right.$ I know that $\left[\left[_{S 2}\right.\right.$ Harry has invited Sue $]$ and ${ }_{S 3}$ Bill Mary $\left.]\right]$.

(27) maps onto the discourse structure shown in (28). The boxed sub-tree corresponds to the discourse representation in (20), in which ellipsis is licensed according to (19).

(28) Discourse tree of (27)

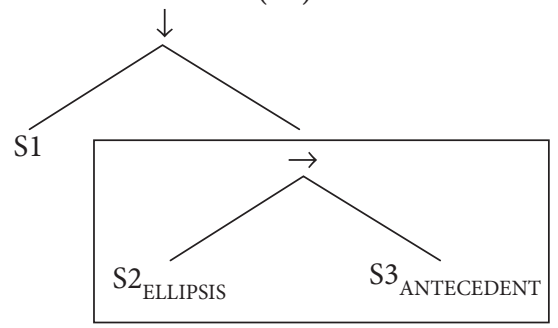

The no subordination restriction on Gapping, illustrated in (29), also follows from (19).

(29) ${ }^{*}\left[_{S 1}\right.$ Max ate the apple], because $\left[_{S 2}\right.$ Sally the hamburger].

The example in (29) has a hierarchical interpretation (just like (18b)). Specifically, S2 specifies the cause for S1. (29) thus maps onto the discourse representation in (30), which is not a configuration in which ellipsis is licensed (cf. (20)). 
(30) Discourse tree of (29)

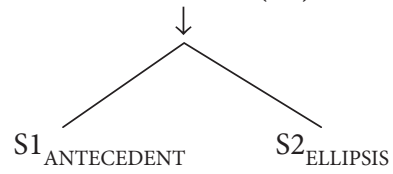

I conclude that (19) correctly captures the distributional facts of Gapping and Fragments discussed in Section 2. Recall that the data in Section 2 gave rise to two questions. What underlies the no subordination restriction on Gapping and Fragments, and why does Sluicing pattern differently from Gapping and Fragments? In this section I have answered the first of these questions. The no subordination restriction on Gapping and Fragments follows from the licensing condition in (19), which states that a non-hierarchical relation must hold between ellipsis clause and antecedent. As it stands, we have yet to answer the second question: Why does the licensing condition in (19) govern Gapping and Fragments, but not Sluicing?

\section{A uniform licensing condition for clausal ellipsis}

It is important to note that, as it stands, the licensing condition in (19), repeated below, is just a stipulation.

(19) Licensing condition on Gapping and Fragments

Gapping and Fragments are licensed when ellipsis and antecedent are in a non-hierarchical relation in the discourse.

Ideally, the condition in (19), proposed to capture Gapping and Fragments, follows from the general licensing condition as postulated in (15).

(15) Licensing condition on clausal ellipsis

Ellipsis is licensed when the ellipsis clause is DISCOURSE-linked to an antecedent.

I argue that, given our assumptions, (19) captures a subset of the cases governed by (15). The key point is that a discourse relation can be established in one of two ways. Either there holds a direct relation between the ellipsis clause and the antecedent or a relation is established anaphorically. For Sluicing, I hypothesized that the wh-phrase DIscourse-links the sluice to an antecedent. This wh-phrase can be seen as a discourse anaphor, which establishes a link between the ellipsis clause and the antecedent (more precisely, the indefinite correlate in the antecedent). Seen in this light, (19) can be taken to state that ellipsis is licensed because a 
direct discourse relation holds between ellipsis clause and antecedent. Discourselinking, therefore, does not have to be mediated by a discourse anaphor/ellipsis licensor. If correct, there is thus no need to state (19) as a separate condition, as it governs a subset of the cases governed by (15).

\section{Conclusion}

In this paper, I have presented an account for why there is a two-way split in the distribution of ellipsis types. On the one hand, there are ellipsis types that do not seem to be distributionally constrained (Sluicing), whereas on the other hand, ellipsis types such as Gapping and Fragments, are severely restricted in their occurrence. Importantly, this difference in distribution goes hand in hand with the presence versus absence of a licensing element. The hypothesis that an ellipsis clause must be DISCOURSE-linked to an antecedent provides an account for this corollary. Under this hypothesis, the direct discourse relation between ellipsis clause and antecedent in Gapping and Fragments eliminates the need for a DISCOURSE-linking ellipsis licensor. ${ }^{4}$ In Sluicing, on the other hand, there is no direct discourse relation between ellipsis clause and antecedent. Therefore, DISCOURSE-linking to an antecedent must be mediated by an ellipsis licensor. The fact that an indirect discourse relation is involved in Sluicing explains why the no subordination restriction does not come into play in this ellipsis type.

\section{Notes}

1. It has been noted in the literature that there are exceptions to the generalization that Gapping and Fragments cannot occur in embedded clauses (e.g. Temmerman 2013). In particular, 'bridge verbs' like say and think do allow Gapping and Fragments in their complement, as in (i), which involves a case of embedded Fragments.

(i) A: Who will come? B: I think John.

However, there is some reason to believe that ellipsis embedded under 'bridge verbs' is not an instance of Gapping or Fragments. Whereas Gapping cannot occur in adverbial clauses (cf. (9)), ellipsis under bridge verbs can, as shown in (ii). Moreover, as illustrated in (iii), ellipsis under bridge verbs can be embedded under verbs such as know that disallow Gapping and Fragments in their complement (cf. (2) and (3)).

(ii) I hope John will win, even though the expert thinks Bill.

(iii) Who arrived? I know you said Bill, but I'd like to hear you say it again.

2. I diverge from López' proposal here to make it compatible with my assumptions. In particular, I do not adopt López's assumption that the licensor in Sluicing is C. Rather, I take it to be the $w h$-phrase itself (cf. Thoms 2010). Support for this comes from the fact that C is always 
empty under ellipsis (Merchant 2001), suggesting that it is part of the ellipsis site and is therefore unlikely to be the licensor (which is typically the sister of the ellipsis site). Also, López assumes that the ellipsis site is a silent pronoun, which has to adjoin to the licensor. This idea is incompatible with the hypothesis that ellipsis sites are full-fledged syntactic structures. None of these assumptions are crucial for the core idea in López's proposal, namely that ellipsis licensors are DISCOURSE-linking elements.

3. Culicover \& Jackendoff (1997) argue at length that asymmetric coordinations feature regular coordinative syntax. The hierarchical interpretation in (22) can therefore not be read off from the syntax. Consequently, the data in (22) are out of reach for syntactic licensing accounts.

4. What the account sketched in this paper does not directly explain is why a non-hierarchical discourse relation does not license ellipsis. I will leave this issue for future research.

\section{References}

AnderBois, Scott. 2011. Sluicing as anaphora to issues. Proceedings of SALT 20. 451-470.

Asher, Nicholas. 1993. Reference to abstract objects in discourse. Boston, MA: Kluwer Academic Publishers. DOI: 10.1007/978-94-011-1715-9

Asher, Nicholas \& Laure Vieu. 2005. Subordinating and coordinating discourse relations. Lingua 115(4). 591-610. DOI: 10.1016/j.lingua.2003.09.017

Blühdorn, Hardarik. 2008. Subordination and coordination in syntax, semantics, and discourse: Evidence from the study of connectives. In Fabricius-Hansen, Cathrine \& Wiebke Ramm (eds.), 'Subordination' versus 'Coordination' in Sentence and Text. Amsterdam: Benjamins.

Culicover, Peter \& Ray Jackendoff. 1997. Semantic subordination despite syntactic coordination. Linguistic Inquiry 28. 195-217.

Hankamer, Jorge. 1979. Deletion in coordinate structure. Garland Pub.

Jackendoff, Ray. 1971. Gapping and related rules. Linguistic Inquiry 2(1). 21-35.

Johnson, Kyle. 2009. Gapping is not (VP-)ellipsis. Linguistic Inquiry 40. 289-328.

DOI: 10.1162/ling.2009.40.2.289

Kim, Jeong-Seok. 1997. Sluicing in English. Studies in Generative Grammar 7. 153-193.

Kratzer, Angelika \& Junko Shimoyama. 2002. Indeterminate pronouns: The view from Japanese. 3rd Tokyo conference on psycholinguistics. 1-25.

Levin, Nancy \& Ellen Prince. 1986. Gapping and causal implicature. Research on Language \& Social Interaction 19. 351-364.

Lobeck, Anne. 1995. Ellipsis: Functional heads, licensing, and identification. Oxford: Oxford University Press.

López, Luis. 2000. Ellipsis and discourse-linking. Lingua 110. 183-213.

DOI: 10.1016/S0024-3841(99)00036-4

Merchant, Jason. 2001. The syntax of silence: Sluicing, islands, and the theory of ellipsis. Oxford: Oxford University Press.

Van Riemsdijk, Henk. 1978. A case study in syntactic markedness: The binding nature of prepositional phrases. Dordrecht: Foris.

Rizzi, Luigi. 1990. Relativized minimality. Cambridge, MA: The MIT Press. 
Temmerman, Tanja. 2013. The syntax of Dutch embedded fragment answers: On the PF-theory of islands and the wh/sluicing correlation. Natural Language \& Linguistic Theory 31. 235285. DOI: $10.1007 / \mathrm{s} 11049-012-9180-6$

Thoms, Gary. 2010. 'Verb floating' and VP-ellipsis: Towards a movement account of ellipsis licensing. Linguistic Variation Yearbook 10. 252-297. DOI: 10.1075/livy.10.07tho

Webber, Bonnie, Aravind Joshi, Matthew Stone \& Alistair Knott. 2003. Anaphora and discourse structure. Computational Linguistics 29(4). 545-587. DOI: 10.1162/089120103322753347

\section{Author's address}

Enrico Boone

Leiden University Centre for Linguistics

P.O. Box 9515

2300 RA Leiden, The Netherlands

E.Boone@hum.leidenuniv.nl 